\title{
OPTIMIZATION TECHNIQUE FOR MANPOWER TRAINING IN TECHNICAL COLLEGE
}

\author{
Manoj Kumar Mandal ${ }^{*}$, Arun Prasad Burnwal ${ }^{2}$, Avinash Kumar ${ }^{3}$ \\ $1^{*}$ Department of Mathematics, Jharkhand Rai University, Ranchi, India; ${ }^{2}$ Department of Mathematics, GGSESTC, \\ Bokaro, Jharkhand, India; ${ }^{3}$ Ramgarh Engineering College, Ramgarh, Jharkhand, India. \\ Email: ${ }^{1 *}$ mkmandal346@gmail.com, ${ }^{2}$ apburnwal@yahoo.com, ${ }^{3}$ avikr1208@gmail.com
} Article History: Received on $12^{\text {th }}$ April 2020, Revised on $26^{\text {th }}$ May 2020, Published on $16^{\text {th }}$ June 2020

\begin{abstract}
Purpose: In the modern era, the number of technical colleges increases rapidly due to the huge growth of the students. But the number of teachers is less compare to the number of students. So, there is a need for optimization of manpower in the institutes.
\end{abstract}

Methodology: In this paper, mathematical optimization is used with the help of linear programming by using permanent, contractual, and adjunct faculties with the help of three objectives for the engineering department, general department, and non-teaching staffs.

Main Finding: Finally, the outcome of the paper is different optimal values for three stated objectives.

Implication: The proposed method is the mathematical formulation of the optimization in a technical institute.

The novelty of Study: This paper deals with a mathematical model of manpower problem. A sample problem has solved to illustrate the procedure.

Keywords: Manpower Training Programme, LPP, Programming Model, LINGO Software.

\section{INTRODUCTION}

In the current scenario, the number of technical colleges is increasing rapidly due to increasing ratio students (Samal, S. S. \& Bharati, A. (2019), Gudi, S. K. et al, (2019)). This college carries several technical courses such as several diplomas like DCA, PGDCA, engineering diploma, several bachelor degrees like B.Tech., BCA, BBA, BSc IT, etc. several master degrees like M. Tech., MCA, MBA, MSc IT, etc. Although, the number of courses increases more, but the number of faculties is too less compared to students and courses (Kaur, A. \& Manhas, R. (2008)), (Patel, N. K. et al., (2018)). Every year, Indian Government rule changes frequently. The main focus of this change to develop our educational quality and help the student in terms of education. AICTE and other Government bodies are continuously forcing for attending the technical course to the faculties that helps to the facilities to growth their knowledge. Everyday man is proposed with many options and choice making. In our life the main complicated and more difficult thing for us in accord with our life. Good knowledge of the judgment that you make after thinking about various possibilities to the skills needed and some techniques to be used to develop sound decision making. In this study determining and choosing among option values, for one thing, more another and values of the individual. An important factor in decision making the existing choice and option. Considering these choices and identify them. The choosing most alternative that can impact success and effectiveness. MPT is a continuous process that is useful for improvement in a job in and continues throughout their careers as it has become a major undertaking for employers (Gray, L. (1993)), (Wilson, J. A. (1983)), (Spaulding, S. (1977)). In this paper, linear programming is used to formulate the proposed paper which is a part of operation research that is used in science and engineering both fields including management study (Gupta, P. K. \& Hira, D. S. (2011)), (Fagoyinbo, I. S. \& Ajibode I. A. (2010)), (Kashyap, M. \& Gupta (2014)). A linear programming model of the MPT has been discussed in this paper. In this paper, values are taken by assumption with randomly for predicting optimal solution.

Let $\mathrm{S}$ is the set different department of the academic institute given by

$\mathrm{S}=\left\{e_{1}\right\}, \mathrm{i}=1,2,3, \ldots \ldots . \mathrm{n} ; \mathrm{k}=17$

Where, $e_{1}=$ Environmental Engineering, $e_{2}=$ Computer Engineering Science, $e_{3}=$ Information $\&$ Technology, $e_{4}=$ Mechanical Engineering, $e_{5}=$ Electronic \& Communication, $e_{6}=$ Electrical Engineering, $e_{7}=$ Civil Engineering,$e_{8}=$ Chemical Engineering, $e_{9}=$ Communication $\&$ Skills, $e_{10}=$ Mathematics, $e_{11}=$ Physics, $e_{12}=$ Chemistry, $e_{13}=$ Yoga, $e_{14}=$ Sport,$e_{15}=$ Administration, $e_{16}=$ T.P.O., $e_{17}=$ Library .

The number of PFM and CFM of each department is as per the Intec same. These numbers vary as per the norms of UGC and AICTE which maintenance the concepts of staffs and teacher ratio. 
Table 1: List of manpower training in the technical college

\begin{tabular}{cccc}
\hline Departments & $\begin{array}{c}\text { Adjunct Faculty } \\
\text { Members(AFM) }\end{array}$ & $\begin{array}{c}\text { Permanent Faculty } \\
\text { Members(PFM) }\end{array}$ & $\begin{array}{c}\text { Contractual Faculty } \\
\text { Members (CFM) }\end{array}$ \\
\hline Teaching Faculty & $a_{1}$ & $p_{1}$ & $c_{1}$ \\
\hline$e_{1}$ & $a_{2}$ & $p_{2}$ & $c_{2}$ \\
\hline$e_{2}$ & $a_{2}$ & $p_{3}$ & $c_{3}$ \\
\hline$e_{3}$ & $a_{3}$ & $p_{4}$ & $c_{4}$ \\
\hline$e_{4}$ & $a_{4}$ & $p_{5}$ & $c_{5}$ \\
\hline$e_{5}$ & $a_{5}$ & $p_{6}$ & $c_{6}$ \\
\hline$e_{6}$ & $a_{6}$ & $p_{7}$ & $c_{7}$ \\
\hline$e_{7}$ & $a_{7}$ & $p_{8}$ & $c_{8}$ \\
\hline$e_{8}$ & $a_{8}$ & $c_{9}$ \\
\hline General Department & & $p_{9}$ & $c_{10}$ \\
\hline$e_{9}$ & $a_{9}$ & $p_{10}$ & $c_{11}$ \\
\hline$e_{10}$ & $a_{10}$ & $p_{11}$ & $c_{13}$ \\
\hline$e_{11}$ & $p_{12}$ & $c_{14}$ \\
\hline$e_{12}$ & $a_{12}$ & $p_{13}$ & $c_{15}$ \\
\hline$e_{13}$ & $a_{13}$ & $p_{14}$ & $c_{16}$ \\
\hline$e_{14}$ & $a_{14}$ & $c_{15}$ & \\
\hline Non- Teaching Faculty & & $p_{16}$ & $c_{17}$ \\
\hline$e_{15}$ & $a_{15}$ & $p_{16}$ & \\
\hline$e_{16}$ & $a_{16}$ & & \\
\hline$e_{17}$ & $a_{17}$ & & \\
\hline
\end{tabular}

Description of Mathematics Model on the following Section

Section 1: Adjunct Faculty Members (AFM)

2: Permanent Faculty Members (PFM)

3: Contractual Faculty Members (CFM)

It is assumed that the department has the same Intec.

Model is based on the assumption that $\mathrm{X}_{1}$ for $\mathrm{AFM}, \mathrm{X}_{2}$ for PFM and $\mathrm{X}_{3}$ for CFM.

For Adjunct faculty members, Permanent faculty members and Contractual members sections.

Engineering Department:

Teaching Members

Minimize: $\mathrm{Z}=x_{1}+x_{2}+x_{3}$

Subject to constraints:

$$
\begin{aligned}
& a_{1} x_{1}+p_{1} x_{2}+c_{1} x_{3} \geq n_{1} \\
& a_{2} x_{1}+p_{2} x_{2}+c_{2} x_{3} \geq n_{1} \\
& a_{3} x_{1}+p_{3} x_{2}+c_{3} x_{3} \geq n_{1} \\
& a_{4} x_{1}+p_{4} x_{2}+c_{4} x_{3} \geq n_{1} \\
& a_{5} x_{1}+p_{5} x_{2}+c_{5} x_{3} \geq n_{1} \\
& a_{6} x_{1}+p_{6} x_{2}+c_{6} x_{3} \geq n_{1} \\
& a_{7} x_{1}+p_{7} x_{2}+c_{7} x_{3} \geq n_{1} \\
& a_{8} x_{1}+p_{8} x_{2}+c_{8} x_{3} \geq n_{1} \\
& x_{1}, x_{2}, x_{3} \geq 0
\end{aligned}
$$

\section{Teaching Members}

General Department Minimize: $\mathrm{Z}=\mathrm{x}_{1}+\mathrm{x}_{2}+\mathrm{x}_{3}$ 
Subject to constraints:

$$
\begin{aligned}
& a_{9} x_{1}+p_{9} x_{2}+c_{9} x_{3} \geq n_{2} \\
& a_{10} x_{1}+p_{10} x_{2}+c_{10} x_{3} \geq n_{2} \\
& a_{11} x_{1}+p_{11} x_{2}+c_{11} x_{3} \geq n_{2} \\
& a_{12} x_{1}+p_{12} x_{2}+c_{12} x_{3} \geq n_{2} \\
& a_{13} x_{1}+p_{13} x_{2}+c_{13} x_{3} \geq n_{2} \\
& a_{14} x_{1}+p_{14} x_{2}+c_{14} x_{3} \geq n_{2} \\
& \square_{1}, \square_{2}, \square_{3}, \geq 0
\end{aligned}
$$

Non-Teaching Member

Minimize: $\mathrm{Z}=\square_{1}+\square_{2}+\square_{3}$

Subject constraints:

$$
\begin{aligned}
& a_{15} x_{1}+p_{15} x_{2}+c_{15} x_{3} \geq n_{3} \\
& a_{16} x_{1}+p_{16} x_{2}+c_{16} x_{3} \geq n_{3} \\
& a_{17} x_{1}+p_{17} x_{2}+c_{17} x_{3} \geq n_{3} \\
& x_{1}, x_{2}, x_{3} \geq 0 \\
& \text { where } a_{1=12}, a_{2=13}, a_{3=3}, a_{4=14}, a_{5=12}, a_{6}=13, a_{7=11}, a_{8}=2, a_{9=6}, a_{10=3,} a_{11=2,} a_{12=1}, a_{13=2} \text {, } \\
& a_{14=2}, a_{15=4}, a_{16}=8, a_{17}=2 \text {, and } p_{1=18}, p_{2}=16, p_{3=5}, d_{4=12,}, p_{5=12}, p_{6}=12, p_{7=2}, p_{8}=8, p_{9=6,}, p_{10=3,} p_{11=2}, p_{12=1} \text {, } \\
& p_{13=2,} p_{14=2,} p_{15}=3, p_{16}=2, p_{17=4} \text {, And } c_{1=12}, c_{2}=10, c_{3=17}, c_{4=9,} c_{5=12}, c_{6}=8, c_{7}=5, c_{8}=3, c_{9=2,}, c_{10=2,}, c_{11=3}, c_{12=3} \text {, } \\
& c_{13}=0, c_{14=0}, c_{15}=10, c_{16}=5, c_{17=1}, n_{1=8}, n_{2}=8, n_{3=8} \text {. }
\end{aligned}
$$

\section{The solution is obtained as}

The Models were analysed using computer software LINGO. The results are in the form of an integer optimum solution. The integer optimum solution is obtained because the decision variable is representing a human being where we cannot have decimals or a fraction of human beings.

\section{Teaching Member}

Engineering Department

Optimum: $\mathrm{Z}=1.860465, X_{1}=0.1860465, X_{2}=1.302326$, and $X \square_{3}=0.3720930$ Integer

Optimum: $\mathrm{Z}=2, X_{1}$ (Adjunct Faculty Members)=1, $X_{2}$ (Permanent Faculty Members)=1, $X_{3}$ (Contractual Faculty Members) $=1$ From the solution to the model for teaching members (engineering department) using integer optimum solution the minimized objective function is given as $\mathrm{Z}=3$. Which says that 2 (two) of the Adjunct faculty members, 1 (one) of the Permanent faculty member and 1 (one) Contractual faculty member should be sent for a training programme.

$\mathrm{CO} 1=$ cost of $\mathrm{AFM}$

$\mathrm{CO} 2=$ cost of PFM

$\mathrm{CO} 3=$ Cost of CFM Following result obtained by using LINGO soft.

Teaching Members

General Department

Optimum: $\mathrm{Z}=4.80000, X_{1}=3.20000, X_{2}=1.60000$, and $X_{3}=0.00000$ Integer

Optimum: $\mathrm{Z}=5, X_{1}$ (Adjunct Faculty Members) = 3, $X_{2}$ (Permanent Faculty Members) $=2, X_{3}$ (Contractual Faculty Members) $=0$ From the solution to the model for teaching members (General department) using integer optimum solution the minimized objective function is gives as $\mathrm{Z}=5$. Which says that 3 (three) of the Adjunct faculty members, 2 (two) of the Permanent faculty member and 0 (zero) Contractual faculty member should be send for training programme.

$\mathrm{CO} 1=$ cost of AFM

$\mathrm{CO} 2=$ cost of $\mathrm{PFM}$ 
$\mathrm{CO} 3=$ Cost of CFM Following result obtained by using LINGO soft.

Non-Teaching Members

Optimum: $\mathrm{Z}=2.317757, X_{1}=0.52333645, X_{2}=1.719626$, and $X_{3}=0.7476636 \mathrm{E}-01$ Integer

Optimum: $Z=2, X_{1}$ (Adjunct Faculty Members) $=1, X_{2}$ (Permanent Faculty Members) $=2, X_{3}$ (Contractual Faculty Members $)=1$ From the solution to the model for non- teaching members using integer optimum solution the minimized objective function is given as $Z=2$. Which says that 1 (one) of the Adjunct faculty members, 2 (two) of the Permanent faculty member and 1 (one) Contractual faculty member should be sent for a training programme.

$\mathrm{CO} 1=$ cost of AFM

$\mathrm{CO} 2=$ cost of PFM

$\mathrm{CO} 3=$ Cost of CFM Following result obtained by using LINGO soft.

\section{CONCLUSION}

In this paper, the study is to apply Linear programming manpower training in technical college the effective use of resources for training in technical college form teaching and non- teaching unit of the institute. There is the following research uses different number of Adjunct Faculty members, permanent Faculty member, and contractual faculty members from the different department under these units in this model.

\section{REFERENCES}

1. Fagoyinbo, I. S. \& Ajibode I. A. (2010). Application of Linear Programming Techniques in the Effective Use of Resources for Staff Training. (JETAS) I (2) (2010) 127- 132.

2. Gray, L. (1993). The role of training providers in manpower planning. The Vocational Aspect of Education, 45(3), pp. 251-263. https://doi.org/10.1080/0305787930450306

3. Gudi, S. K., Chhabra, M. \& Rashid, M. (2019). Assessment of the impact of pharmacist-led face-to-face counselling on HIV/AIDS among school \& college going students, and infected patients in south India. Clinical Epidemiology and Global Health. https://doi.org/10.1016/j.cegh.2019.01.006

4. Gupta, P. K. \& Hira, D. S. (2011). Operation Research. Delhi S. Chand Publishers, 2011,

5. Kashyap, M. \& Gupta (2014). Application of Linear Programming Techniques for Staff Training. (IJEIT) (2014) Vol.3.SSS

6. Kaur, A. \& Manhas, R. (2008). Use of Internet services and resources in the engineering colleges of Punjab and Haryana (India): A study. The International Information \& Library Review, 40(1), pp. 10-20. https://doi.org/10.1080/10572317.2008.10762759

7. Patel, N. K., Nivethitha, L. \& Mooventhan, A. (2018). Effect of a Yoga Based Meditation Technique on Emotional Regulation, Self-compassion and Mindfulness in College Students. Explore, 14(6), pp. 443-447. https://doi.org/10.1016/j.explore.2018.06.008

8. Samal, S. S. \& Bharati, A. (2019). Gaps in engineering education with a categorical analysis on nanotechnology in India. Materials Today: Proceedings, 10, pp. 121-135. https://doi.org/10.1016/j.matpr.2019.02.197

9. Spaulding, S. (1977). Educational planning: Who does what to whom and with what effect?. Comparative Education, 13(1), pp. 55-67.

10. Wilson, J. A. (1983). Manpower planning and the staffing needs of schools. British Journal of Educational Studies, 31(2), pp. 131-140. https://doi.org/10.1080/00071005.1983.9973652 